\title{
Pengaruh jarak transportasi terhadap biokimia darah ayam broiler
}

\section{Effect of transportation distance on broiler blood biochemistry}

\author{
Bagus Aji Purwadi, Teysar Adi Sarjana*, dan Retno Murwani \\ Fakultas Peternakan dan Pertanian Universitas Diponegoro \\ J1. Prof. H. Soedarto, S.H. - Tembalang Semarang, Indonesia (50275) \\ Submitted: 09 July 2018, Accepted: 28 July 2018
}

\begin{abstract}
ABSTRAK: Penelitian bertujuan mengkaji pengaruh jarak transportasi terhadap parameter biokimia darah ayam broiler yang meliputi kadar hemoglobin, hematokrit, eritrosit, glukosa, trigliserida dan kolesterol darah. Ayam broiler sebanyak 252 ekor dengan bobot badan ayam 2,0 $\pm 0,08 \mathrm{~kg}$ dibagi menjadi 3 jarak transportasi yang berbeda yaitu T1: Jarak $60 \mathrm{~km}$, T2: Jarak $120 \mathrm{~km}$, T3: Jarak $180 \mathrm{~km}$. Data yang diperoleh dianalisis ragam dan diuji lanjut dengan uji beda Duncan. Jarak transportasi yang lebih jauh menurunkan jumlah hemoglobin, hematokrit dan trigliserida secarasignifikan $(\mathrm{P} \leq 0,05)$. Jumlah eritrosit, kadar glukosa dan kadar kolesterol tidak dipengaruhi jarak transportasi $(\mathrm{P}>0,05)$. Kesimpulan dari penelitian ini transportasi broiler pada jarak $120 \mathrm{~km}$ sudah berdampak negative terhadap yaitu menurunkan kadar hemoglobin, hematokrit dan trigliserida.
\end{abstract}

Kata Kunci: jarak transportasi, broiler, hemoglobin, hematokrit, glukosa, trigliserida, kolesterol

ABSTRACT: The objective of this research is to examine the effect of transportation distance on haemoglobin, hematocrit, erythrocytes, plasmaglucose, triglyceride and cholesterol of broilers. Two hundred and fifty two broilers with an average body weight of $2.0 \pm 0.08 \mathrm{~kg}$ were dividedinto transportation distance namely T1: $60 \mathrm{~km}, \mathrm{~T} 2: 120 \mathrm{~km}, \mathrm{~T} 3: 180 \mathrm{~km}$. The data were analyzed by Anova whenthere was a significant effect Duncan test was conducted. Longer transportation distance significantly decreased plasma hemoglobin, hematocrit and triglyceride $(\mathrm{P} \leq 0,05)$, while erythrocytes, glucose and cholesterol level were not significantly affected $(\mathrm{P}>0.05)$. The conclusion of this study is broiler transport at a distance of $120 \mathrm{~km}$ has reduced hemoglobin, hematocrit, and plasma triglyceride levels.

Keywords: transportation distance, broiler, hemoglobin, hematocrit, glucose, triglycerides, cholesterol

\section{PENDAHULUAN}

Lokasi peternakan ayam broiler biasanya terletak jauh dari rumah pemotongan ayam, sehingga dibutuhkan transportasi untuk membawa broiler ke tempat pemotongan. Proses transport dapat mengakibatkan stress pada broiler akibat perbedaan lingkungan selama transport seperti guncangan, posisi dankepadatan keranjang pengangkut, jarak transport, dan tidak adanya pakan dan minum selama transport. Stress pada broiler selama transport dapat dilihat melalui berbagai parameter darah, karena darah berfungsi sebagai alat transport nutrisi, oksigen, karbon dioksida, berbagai metabolit, hormon, panas, dan mediator untuk mempertahankan kesehatan
(Satyaningtijas dkk. 2010; Rachied, 2014). Profil darah merah yaitu hemoglobin, hematokrit dan eritrosit dapat terpengaruh oleh stress. Penelitian oleh Ondrasovicova dkk. (2008) menunjukkan bahwa jarak transport $30 \mathrm{~km}$ dapat menurunkan hemoglobin. Pada jarak transport lebih jauh yaitu $120 \mathrm{~km}$ terjadi penurunan hemoglobin yang lebih besar dibandingkan jarak $30 \mathrm{~km}$. Penelitian oleh Zhang dkk., (2009) menunjukkan bahwa transport broiler selama 45 menit menyebabkan penurunan glukosa darah. Penelitian lain mendapatkan hasil yang berbeda yaitu setelah transport sejauh $70 \mathrm{~km}$, kadar glukosa darah tidak berubah, tetapi kadar trigliserida turun signifikan (Vosmerova dkk., 2010). Transport sejauh

*Corresponding Author: teysar_adi@undip.ac.id

DOI: 10.21776/ub.jiip.2018.028.02.05 
51 sampai $100 \mathrm{~km}$ menyebabkan kematian $0,31 \%$ dan pada jarak yang lebih jauh melebihi $300 \mathrm{~km}$ kematian mencapai 0,72\% (Vecerek dkk., 2016). Penelitian ini bertujuan untuk mengetahui pengaruh jarak trasportasi terhadap status biokimia darah ayam broiler yang meliputi kadar hemoglobin, hematokrit, seldarah merah, glukosa, trigliserida, dankolesterol darah. Penelitian ini diharapkan dapat memberikan informasi tentang pengaruh jarak trasportasi terhadap status biokimia darah ayam broiler.

\section{MATERI DAN METODE}

\section{Materi}

Materi yang digunakan dalam penelitian ini meliputi ayam broiler sebanyak 252 ekor dengan rata-rata bobot badan ayam $1.93 \pm 0,08 \mathrm{~kg}$ yang dipanen pada umur 30 hari dari kandang closed house Fakultas Peternakan dan Pertanian Universitas Diponegoro, Semarang.

Peralatan yang digunakan antara lain timbangan kapasitas $50 \mathrm{~kg}$ untuk menimbang ayam, Mobil pick up untuk sarana transportasi ayam, 21 unit keranjang dengan ukuran 94x57x28 cm untuk tempat ayam selama transportasi, kestrel untuk mengukur suhu, kelembaban dan temperature humidity index (THI), sun radiator measuring temperature untuk mengukur radiasi matahari, spuit $3 \mathrm{ml}$ untuk mengambil sampel darah, tabung yang telah berisi antikoagulan EDTA dan cooling box untuk menyimpan sampel darah.

\section{Metode}

Pelaksanaan transportasi dimulai dari kandang closed house Fakultas Peternakan dan Pertanian, Universitas Diponegoro, Semarang dan ditransportasikan dengan jarak $60 \mathrm{~km}, 120 \mathrm{~km}$ dan $180 \mathrm{~km}$ sampai kembali lagi ke kandang close house Fakultas Peternakan danPertanian, Universitas Diponegoro, Semarang sebagai representasi jarak tempuh ke rumah pemotongan ayam (RPA). Jarak transportasi tersebut diadaptasi dari salah satu standar operasional rumah potong ayam skala besar di Jawa Tengah. Pelaksanaan transportasi dilakukan semirip mungkin dengan kondisi di lapangan. Gambaran kondisi makrolimat selama masa transportasi disajikan pada Tabel 1.

Tabel 1. Data makrolimat selama transportasi

\begin{tabular}{lccc}
\hline \multirow{2}{*}{ Parameter } & \multicolumn{3}{c}{ Perlakuan } \\
\cline { 2 - 4 } & $\mathrm{T} 1$ & $\mathrm{~T} 2$ & $\mathrm{~T} 3$ \\
\hline Suhu $\left({ }^{\circ} \mathrm{C}\right)$ & 30,53 & 32,50 & 33,17 \\
Kelembaban $(\%)$ & 63,70 & 59,57 & 61,03 \\
Radiasi Matahari $\left(\mathrm{W} / \mathrm{m}^{2}\right)$ & 424,29 & 470,59 & 446,99 \\
\hline
\end{tabular}

Parameter yang diamati yaitu kadar hemoglobin, hematokrit, eritrosit, glukosa, trigliserida dan kolesterol darah. Pengambilan data suhu kelembaban dan radiasi matahari diambil pada saat perjalanan masing-masing jarak transportasi. Sampel darah diambil sebanyak $\pm 2 \mathrm{ml}$ melalui vena brachialis denganmenggunakan spuit $3 \mathrm{ml}$ lalu dimasukkan ke tabung yang telah berisi antikoagulan EDTA. Plasma darah dianalisis untuk penentuan kadar hemoglobin dengan metode ahli, hematokrit dengan metode mikrohematokrit, kadar eritrosit dengan metode Hayem, sedangkan glukosa, trigliserida dan kolesterol plasma diuji dengan metode enzymatic colorimetric test menggunakan reagen fluitest dan dibaca dengan alat spektofotometer.

Penelitian dilakukan dengan metode eksperimental menggunakan rancangan acak lengkap (RAL) dengan 3 perlakuan 7 ulangan (masing-masing ulangan 12 ekor) yaitu T1 : jarak $60 \mathrm{~km}$, T2 : jarak $120 \mathrm{~km}$ da nT3 : jarak $180 \mathrm{~km}$. Data yang diperoleh diuji statistik dengan analisis ragam dan Duncan pada taraf signifikansi 5\%.

\section{HASIL DAN PEMBAHASAN}


Hasil penelitian menunjukkan bahwa jarak transportasi yang lebih jauh signifikan menurunkan $(\mathrm{P} \leq 0,05)$ kadar hemoglobin, hematokrit dan trigliserida, sedangkan jumlah eritrosit, kadar glukosa dan kolesterol tidak signifikan dipengaruhi jarak transportasi $(\mathrm{P}>0,05)$. Data selengkapnya disajikan pada Tabel 2.

Tabel 2. Pengaruh jarak transportasi terhadap biokimia darah

\begin{tabular}{|c|c|c|c|c|c|}
\hline \multirow{2}{*}{ Parameter } & \multicolumn{3}{|c|}{ Perlakuan } & \multirow{2}{*}{$\mathrm{P}$} & \multirow{2}{*}{ SE } \\
\hline & $\mathrm{T} 1(60 \mathrm{~km}$ & $\mathrm{T} 2(120 \mathrm{~km})$ & T3 $(180 \mathrm{~km})$ & & \\
\hline$\overline{\text { Hemoglobin }(\mathrm{g} / \mathrm{dL})}$ & $18,51^{\mathrm{a}}$ & $14,2^{\mathrm{b}}$ & $13,94^{\mathrm{b}}$ & 0,00 & $\overline{0,02}$ \\
\hline Hematokrit (\%) & $55,43^{\mathrm{a}}$ & $45,43^{\mathrm{b}}$ & $41,14^{\mathrm{b}}$ & 0,02 & 0,03 \\
\hline Eritrosit (juta/mm ${ }^{3}$ ) & 2,20 & 2,42 & 2,50 & 0,37 & 0,04 \\
\hline Glukosa (mg/dL) & 159,33 & 154,09 & 166,13 & 0,95 & 0,07 \\
\hline Trigliserida (mg/dL) & $132,16^{\mathrm{a}}$ & $119,96^{\mathrm{ab}}$ & $111,06^{\mathrm{b}}$ & 0,05 & 0,02 \\
\hline Kolesterol (mg/dL) & 162,07 & 162,91 & 162,96 & 0,99 & 6,68 \\
\hline
\end{tabular}

Keterangan : Superskrip berbedapada baris yang sama menunjukkan perbedaan signifikan $(\mathrm{P}<0,05)$.

Berdasarkan Tabel 2, pada T1 (jarak $60 \mathrm{~km}$ ) kadar hemoglobin 18,51 g/dl, pada T2 (jarak $120 \mathrm{~km}$ ) kadar hemoglobin lebih rendah dari T1 yaitu 14,20 g/dl, danpada T3 (jarak 180 km) kadar hemoglobin juga lebih rendah dari $\mathrm{T} 1$ yaitu 13,94 g/dl. Kadar $\mathrm{Hb}$ broiler setelah menempuhjarak transportasi 120 $\mathrm{km}$ dan $180 \mathrm{~km}$ sama. Penurunan $\mathrm{Hb}$ ini dapat disebabkan karena stress panas selama proses transportasi berlangsung yang mengakibatkan terjadinya peningkatan frekuensi nafas sebagai upaya pembuangan panas tubuh. Hasil penelitian ini sama dengan hasil penelitian Ondrasovicova dkk (2008) dimana jarak transportasi $30 \mathrm{~km}$ sudah menurunkan kadar hemoglobin, dan transportasi lebih jauh dengan jarak120 km kadar hemoglobin nyata makin rendah dibandingkan jarak pengangkutan $30 \mathrm{~km}$.

Kadar eritrosit pada darah ayam broiler tidak dipengaruhi oleh jaraktransportasi. Fungsi utama dari eritrosit adalah sebagai pembawa hemoglobin yang mengikat oksigen dari paru-paru dan diedarkan ke seluruh sel-sel jaringan. Stres panas dapat menyebabkan jumlah eritrosit dan kadar hemoglobin berubah. Hal ini diduga berkaitan dengan lebih banyak cairan tubuh yang dikeluarkan untuk mengatasi stress panas, sehingga terjadi perubahan bentuk yang tidak normal pada eritrosit dan menyebabkan hemoglobin yang terikat akan terlepas (Rosita dkk, 2015).

Kadar hematokrit broiler setelah ditransportasikan pada jarak yang lebih jauh mengalami penurunan secara signifikan. Pada Tabel 2, T1 (jarak 60 km) kadar hematokrit 55,43 \%, pada T2 (jarak $120 \mathrm{~km}$ ) kadar hematokrit 45,44\%, lebih rendah dari T1, dan pada T3 (jarak $180 \mathrm{~km}$ ) kadar hematokrit 41,14\%, juga lebih rendah dari $\mathrm{T} 1$ tetapi sama dengan T2. Nilai hematokrit tergantung pada volume sel-sel darah yang dibandingkan dengan volume darah keseluruhan (Rosita dkk, 2015). Penurunan kadar hematokrit diduga disebabkan oleh ukuran atau bentuk yang tidak sempurna dari eritrosit karena berkurangnya kadar hemoglobin sehingga presentase volume sel darah merah menjadi berkurang. Kadar hematokrit dipengaruhi oleh beberapa faktor, yaitu umur, jenis kelamin, status nutrisi, keadaan hipoksia, jumlah 
eritrosit, dan ukuran eritrosit (Ali dkk., 2013).

Kadar glukosa pada darah ayam broiler setelah ditransportasikan tidak berubah. Hasil kadar glukosa plasma dalam penelitian ini sejalan dengan hasil penelitian dari Vosmerova dkk., (2010) yang melaporkan bahwa kadar glukosa tidak dipengaruhi transportasi dengan jarak $70 \mathrm{~km}$. Pada Tabel 1 dapat dilihat bahwa suhu lingkungan pada saat transportasi semakin meningkat dari T1 sampai T3. Stres oleh panas akan membuat broiler memerlukan pengaturan suhu tubuh internal agar tetap konstan. Pengaturan ini membutuhkan energi melalui pemecahan glukosa, sehingga kadar glukosa dalam darah perlu dijaga tetap konstan. Kadar glukosa yang tidak berbeda secara signifikan diduga dicapai melalui glukoneogenesis yaitu pembentukan glukosa baru (Murwani, 2010). Pembentukan glukosa baru ini dapat berasal dari gliserol hasil pemecahan trigliserida.

Kadar trigliserida pada darah ayam broiler setelah ditransportasikan mengalami penurunan secara signifikan. Pada Tabel 2, T1 (jarak 60 km) kadar trigliserida 132,16 mg/dl, pada T2 (jarak $120 \mathrm{~km}$ ) kadar trigliserida lebih rendah 9,23\% dari $\mathrm{T} 1$ yaitu $119,96 \mathrm{mg} / \mathrm{dl}$ danpada T3 (jarak $180 \mathrm{~km}$ ) kadar trigliserida juga lebih rendah $15,96 \%$ dari T1 tetapi tidak berbeda nyata dengan T2 yaitu 111,06 mg/dl. Penurunan kadar trigliserida disebabkan karena terjadi pemecahan trigliserida untuk penyediaan energy saat sumber energy dari glukosa sudah mulai berkurang (Murwani, 2010). Pemecahan trigliserida menghasilkan gliserol dan asam-asam lemak. Pemecahan lanjut asam-asam lemak akan menghasilkan energi, sedangkan gliserol dapat digunakan untuk glukoneogenesis. Semakin jauh jarak transportasi, broiler tidak saja mengalami cekaman stress panas tetapi jugapuasa (tanpa pakan dan minum) yang lebih lama. Dalam keadaan puasa disertai cekaman panas, maka akan terjadi pemecahan trigliserida. Hasil penelitian ini sesuaid engan hasil penelitian Vosmerova dkk, (2010) yang mendapatkan hasil bahwa transportasi dengan jarak $70 \mathrm{~km}$ sudah menurunkan kadar trigliserida secara signifikan sebesar 5,35\%.

Kadar kolesterol plasma broiler tidak berubah oleh adanya transportasi. Hal ini kemungkinan karena kolesterol merupakan senyawa metabolit penting yaitu sebagai komponen penyusun membrane sel, precursor hormon steroid dan garam empedu yang diatur melalui homeostasis. Nampaknya glukosa dan kolesterol darah karena peranan masingmasing yang penting untuk dijaga maka keduanya tidak berubah dan merupakan hasil adaptasi selama transport (Daniels dkk., 2009; Mushawwir dan Latipudin, 2011).

\section{KESIMPULAN}

Transportasi broiler pada jarak $120 \mathrm{~km}$ sudah berdampak negative terhadap biokimia darah ayam broiler yaitu menurunkan kadar hemoglobin, hematokrit dan trigliserida darah. Namun tidak berpengaruh secara signifikan kepada kadar eritrosit, glukosa dan kolesterol darah broiler.

\section{DAFTAR PUSTAKA}

Ali, A.S., Ismoyowati, dan D. Indrasanti. 2013. Jumlah eritrosit, kadar hemoglobin dan hematokrit pada berbagai jenis itik lokal terhadap penambahan probiotik dalamransum. Jurnal Ilmiah Peternakan, 1(3), 1001-1013

Daniels, T. F., K. M. Killinger, J. J. Michal, R. W. Wright dan Z. Jiang. 2009. Lipoproteins, cholesterol homeostasis and cardiac 
health. International Journal of Biological Sciences, 5(5), 474488.

Mushawwir A. dan Latipudin, D. 2011. Beberapa Parameter Biokimia Darah Ayam Ras Petelur Fase Grower dan Layerdalam Lingkungan Upper Zonathermoneutral Indonesia. Jurnal Peternakan Indonesia, 13(3), 191 198.

Murwani, R. 2010. Broiler Modern. Semarang: Widya Karya.

Ondrasovicova O, Saba L, Smirjakova S, Vargova M, Ondrasovic M, Mata M, Lakticova K, Wnuk W. 2008. Effects of vehicle-road transport on blood profile in broiler chickens. J Medycna Wet, 64(3), 292293.

Rachied, H.G.A., Zaahkouk S. A., Zawhry E. and Elfeky, K. 2014. Hematological and Biochemical Parameters in Some Bird and Mammals. Journal of Entomology and Zoology, 2(2), 153-158.

Rosita, A., Mushawwir, D dan Latipudin. 2015. Status hematologis (eritrosit, hematokrit, dan hemoglobin) ayam petelur fase layer pada temperature humidity index yang berbeda. Students e-Journal. $4(1)$.

Satyaningtijas A.S., Widhyari S.D., dan R. D. Natalia. Jumlah Eritrosit, Nilai Hematokrit, dan Kadar Hemoglobin Ayam Pedaging Umur 6 Minggu Dengan PakanTambahan. Jurnal Kedokteran Hewan, 4(2), 69-73.
Vecerek V., Voslarova E., Conte F., Vecerkova L., and Iveta B. 2016. Negative Trends in Transport-related Mortality Rates in Broiler Chickens. J. Anim. Sci, 29(12), 1796-1804.

Vosmerova, P., J. Chloupek, I. Bedanova, P. Chloupek, K. Kruzikova, J. Blahova, dan V. Vecerek. 2010. Changes in selected biochemical indices related to transport of broilersto slaughterhouse under different ambient temperatures. Poultry Science, 89(12), 2719-2725.

Zhang, L., H.Y Yue, H.J. Zhang, L. Xu, S.G. Wu, H.J. Yan, Y.S. Gong. And G.H Qi. 2009. Transport stress in brolers: Blood metabolism, glycolytic potential, and neat quality. Poult. Sci 88(10), 2033-2041. 